\title{
Prognostic Value of Tissue-Resident Memory T Cells and Tumor Microenvironmental Features in Resected Pancreatic Adenocarcinoma
}

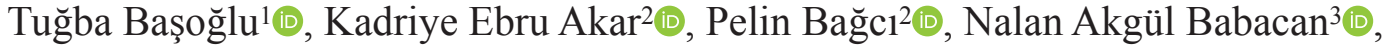 \\ Mehmet Akif Öztürk ${ }^{4}{ }^{\circledR}$, Fatih Emin Öztürk ${ }^{5}$, Nazım Can Demircan ${ }^{1}{ }^{\circledR}$, Rukiye Arıkan ${ }^{1}$, \\ Tuğba Akın Telli1 ${ }^{\mathbb{D}}$, Özlem Ercelep ${ }^{1}\left[\right.$, Faysal Dane ${ }^{1} \mathbb{D}$, Perran Fulden Yumuk ${ }^{1} \mathbb{D}$ \\ ${ }^{1}$ Department of Medical Oncology, Marmara University School of Medicine, İstanbul, Turkey \\ ${ }^{2}$ Department of Pathology, Marmara University School of Medicine, İstanbul, Turkey \\ ${ }^{3}$ Department of Medical Oncology, Bahrain Oncology Center, Al Sayh, Bahrain \\ ${ }^{4}$ Department of Medical Oncology, Bahçeşehir University School of Medicine, İstanbul, Turkey \\ ${ }^{5}$ Department of Internal Medicine, Marmara University School of Medicine, İstanbul, Turkey
}

Background: Pancreatic ductal adenocarcinoma differs from other solid tumors with its unique immunosuppressive microenvironment and non-immunogenic feature. There are not many studies in the literature investigating the effect of these features on prognosis.

Aims: To investigate the prognostic value of tissue-resident memory $\mathrm{T}$ cells, tumor microenvironment features, and tumor-associated immune cells in resected pancreatic ductal adenocarcinomas.

Study Design: Retrospective cross-sectional study.

Methods: Of 138 patients diagnosed with pancreatic ductal adenocarcinoma between 2011 and 2018, 81 were included in the study. Specimens from operated patients were reassessed separately as peritumoral and intratumoral areas for tissue resident memory cells and tumor microenvironmental elements (tumor infiltrating lymphocytes, tumor stroma, CD204+ macrophages, PDL1+ immune cells). Disease-free survival and overall survival were defined from the date of operation to the date of recurrence and the date of first diagnosis to the date of death, respectively. If the patient was alive, the last visit date was taken into account.

Results: The median age at diagnosis was 63 (range: 40-78). The median follow-up period was 18.9 months (range: 1.4-80.4 months).
Median overall survival was 23.7 months (1.4-80.4 months) and median disease-free survival was 10.8 months (1.4-74.4 months).

Patients with higher intra-tumoral tissue-resident memory cell counts had a longer survival trend than those having lower values (25.6 months vs. 18 months, respectively, $P=.84$ ). According to microenvironmental evaluations, lower stromal score (defined as stroma having less desmoplasia and rich in cells) and presence of peritumoral Crohn's-like inflammatory response were associated with higher survival (29.2 months vs. 19.7 months for low vs. high stromal scores, respectively, $P=.16$ and 30.2 months vs. 18.1 months for the presence of Crohn's-like inflammatory response $P=.13$ ). Decreased survival was observed in tumors with increased CD204+ tumorassociated macrophages which were immunosuppressive elements of the microenvironment (12 months vs. 26.3 months for intra-tumoral assessment, $P=.29$ ).

Conclusion: Tissue-resident memory $\mathrm{T}$ cells and other microenvironmental features may be prognostic in resectable pancreatic ductal adenocarcinomas. Further studies with larger cohorts are needed for validation.

The manuscript was presented in $4^{\text {th }}$ National Immunotherapy and Oncology Congress (October 29-November 1, 2020, Turkey) as an oral presentation and was chosen as the best presentation.

Corresponding author: Tuğba Başoğlu, Department of Medical Oncology, Marmara University School of Medicine, İstanbul, Turkey

e-mail: basoglutugba@gmail.com

Received: March 28, 2021 Accepted: September 24, 2021 Available Online Date: January 18, 2022 • DOI: 10.5152/balkanmedj.2021.21122

Available at www.balkanmedicaljournal.org

ORCID iDs of the authors: T.B. 0000-0002-2059-5502; K.E.A. 0000-0003-1512-1166; P.B. 0000-0002-6656-8227; N.A.B. 0000-0001-6006-4290

M.A.Ö. 0000-0003-1365-7944; F.E.Ö. 0000-0002-8075-7307; N.C.D. 0000-0001-6630-5278; R.A. 0000-0003-2688-1515; T.A.T. 0000-0001-6535-6030;

Ö.E. 0000-0001-5892-3519; F.D. 0000-0001-6584-902X; P.F.Y. 0000-0001-8650-299X.

Cite this article as:

Başoğlu T, Ebru Akar K, Bağc1 P, et al. Prognostic Value of Tissue-Resident Memory T Cells and Tumor Microenvironmental Features in Resected Pancreatic

Adenocarcinoma. Balkan Med J.; 2022; 39(1):12-20.

Copyright@Author(s) - Available online at http://balkanmedicaljournal.org/ 


\section{INTRODUCTION}

Pancreatic ductal adenocarcinoma (PDAC) has an increasing incidence. Its prognosis is still poor with a 5-year survival rate being less than $10 \%$. Only $20 \%$ are in the resectable stage at the time of diagnosis. ${ }^{1}$

Unlike other solid tumors, immunotherapies have not achieved expected success in PDAC. Studies aiming to increase the immunogenicity of pancreatic cancer are a topic of interest.

One of the most important reasons why pancreatic cancer is often unresponsive to standard treatments is the complex tumor microenvironment (TME), which has unique characteristics. Pancreatic microenvironment is hypoxic and has poor vascular perfusion. ${ }^{2}$ It acts as a physical and biological barrier and blocks penetration of chemotherapy, immunotherapeutic agents, and immune cells into the tumor. Therefore, TME blocks immune response with its immunosuppressive feature.

As in the concept of "cold tumor" defined in the literature for nonimmunogenic tumors such as the pancreatic carcinomas, despite these inflammatory cells being concentrated around the tumor, there is a low number of tumor-infiltrating lymphocytes (TILs) in the tumor center. ${ }^{3}$ The reason for reduced $\mathrm{T}$ cell infiltration into the tumor might be lack of tumor antigenicity, defected antigenpresenting cells, cytokines responsible for $\mathrm{T}$ cell inactivation, or lack of $\mathrm{T}$ cell penetration into the tumor bed due to tumor stroma known as biological barrier., ${ }^{4,5}$ This definition is the main idea that requires evaluating tumor separately as intratumoral and peritumoral areas.

One of the most critical components of TME is CD8+ memory $\mathrm{T}$ cells which can be classified into 3 groups: 1) circulating effector memory (TEM), 2) central memory (TCM), and 3) non-circulating tissue-resident memory (TRM) cells. ${ }^{6}$ TRM T cells permanently reside in the tissue even if there is no antigenic stimulation. Many transcription factors and adhesion molecules are involved in the interaction between TRM and tumor cells. Most-commonly known marker expressing on the surface of TRM cells was CD103. CD103 is the $\alpha \mathrm{E}$ subunit of the heterodimeric $\alpha \mathrm{E} \beta 7$ integrin molecule and plays an important role in adhesion, migration, and signal transmission. CD103 is also a receptor for E-cadherin which is also an important adhesion molecule. Increased expression of E-cadherin and other adhesion molecules enhance the mobilization of cytotoxic granules and improve the cytotoxic effects of T cells. ${ }^{7}$ Reduced expression of E-cadherin in pancreatic cancer has been shown to be associated with advanced stage and higher histological grade. ${ }^{8}$ Epithelial cells and various immune cells can express CD103. The majority of these immune cells are natural killer cells, natural killer-like $\mathrm{T}$ cells, mast cells, dendritic cells, and especially CD8+ and CD4+ T cells. ${ }^{9}$ Among these, CD103 expressing CD8+ $\mathrm{T}$ cells are closely linked to tumor immune response. ${ }^{10}$

The prognostic value of TRM cells on the survival of cancer is the subject of current studies. It has been shown that an increased number of TRM cells is associated with increased survival in tumors such as lung cancer, ${ }^{11}$ breast cancer ${ }^{12}$ melanoma, ${ }^{13}$ ovarian cancer, ${ }^{14}$ colorectal cancers,${ }^{15}$ and bladder cancer. ${ }^{16}$
Tissue-resident memory $\mathrm{T}$ cells frequently express programmed cell death protein-1 (PD-1). There are studies that showed anti PD-1/PDL-1 treatments increase the activation of TRM cells and improve tumor-associated cytotoxicity in the literature. It is also associated with prolonged survival which has been reported in malign melanoma before. ${ }^{17,18}$

Tumor-associated macrophages (TAM) are important cells of the immune escape. Different subtypes of TAMs have tumor suppressor (M1) and tumor promoter (M2) functions. ${ }^{19}$ CD204, CD206, and CD163 are M2-TAM markers and have been associated with poor prognosis in many cancers. ${ }^{20}$ CD204+ TAMs play an important role in immunosuppression of tumor microenvironment. ${ }^{21}$ Cytokines and chemokines released from macrophages prevent $\mathrm{T}$ cell proliferation and activation. There may be PDL-1 expression on their surface as in $\mathrm{T}$ lymphocytes.

In this study, our aim is to investigate the prognostic value of TRM cells and tumor microenvironment characteristics and tumorassociated immune cells in resected PDACs.

\section{MATERIAL AND METHODS}

\section{Study Design and Patients Selection}

Files of 138 patients diagnosed with PDAC who were followed up in our oncology clinic between July 2011 and December 2018 were retrospectively reviewed. Fifty-seven patients with ampullary and duodenal carcinomas had stage IV tumors that were unresectable and did not have any tumor specimen available for immunohistochemistry, as well as patients with incomplete data in their files were excluded from the study.

A total of 81 patients over the age of 18 that were operated and diagnosed with PDAC and whose paraffin blocks were evaluated at the Department of Pathology were included in the study.

Characteristics of TME were evaluated. All data and observations were recorded. Demographic data, laboratory results, clinical follow-up parameters, treatment responses, and survival information available in the medical oncology files of the patients were recorded. By analyzing the relationship between oncological and pathological data obtained, the markers that could be predictive and prognostic in the clinic were determined.

The current status of the patients without outpatient follow-ups in recent years were contacted by phone, and information was obtained verbally. Ethical approval was taken with a number of 09.2019.483.

\section{Specimen Selection}

All hematoxylin- and eosin-stained tumor slides belonging to 81 cases included in the study were retrieved from the pathology archives and have been re-evaluated. Two tumor samples were selected from each case, 1 principal and 1 substitute. These samples were carefully chosen to reflect both the center and periphery of the tumor and not to contain necrosis and autolysis. 
Pathological tumor stage (T stage) and lymph node stage (N stage) of all cases were re-determined according to the "American Joint Committee on Cancer” (AJCC) 2017 TNM staging system.

\section{Immunohistochemical Evaluation}

The entire immunohistochemical staining process, including deparaffinization and antigen retrieval procedures on sections prepared from formalin-fixed-paraffin-embedded tissues, were performed in a fully automated immunohistochemistry stainer (Ventana BenchMark Ultra, Ventana Medical Systems, Tucson, Ariz). A detection kit (ultraViewTM Universal DAB Detection Kit, Catalog number 760-500, Ventana Medical Systems), which is suitable for the device, containing hydrogen peroxide substrate and DAB chromogen, without biotin, based on HRP multimer was used. CD103 (Leica, EP206 clone, UK), CD204 (Atlas antibodies, polyclonal, Netherlands), PDL-1 (Cell Signaling, E1L3N (R) clone, Netherlands) antibodies were used.

Olympus BX53 model microscope was used for all evaluations of the applied antibodies. Cell counting procedures were also performed using a $40 \mathrm{HPF}$ (high-power field) objective of the same microscope.

\section{Evaluation of CD103}

In the specimens, there were lymphocytes stained positive for CD103 in the duodenal intraepithelial areas, peritumoral pancreatitis areas, inside the tumor, and at the periphery of the tumor. A total of 6 areas was selected for each case for each antibody; the 3 most densely stained areas (hot spots) consisting of intra-tumor lymphocytes and the 3 most intensely stained areas (hot spots) consisting of lymphocytes in the peritumoral stroma were determined by the expert pathologist. After the hot spot selection was completed, positively stained lymphocytes at 40 HPF were counted for each focus (Figure 1a,b).

If concentration of intraepithelial lymphocytes (lymphocytes within the tumor cell) were met, the lymphocyte/tumor ratio was determined by the number of lymphocytes per 100 tumor cells. After counting the stromal lymphocytes in 3 separate foci within the tumor and around the tumor, the arithmetic mean of each was calculated.

CD 103 epithelial staining was not detected in tumor cells or in areas with pancreatitis.

\section{Evaluation of $\mathrm{CD204}$ \\ (MRS-1 Macrophage Scavenger Receptor-1)}

Membranous surface of the macrophages in the tumoral and peritumoral stromal areas was evaluated for CD204 staining. Since staining intensity was the same in almost all of the cases, only the extent of staining was evaluated regardless of the staining intensity (1: minimal, 2: moderate, 3: maximum) (Figure 2a-c).

\section{Evaluation of PDL-1}

Staining of plasma cells for PDL-1 was accepted as the internal control. Staining of placenta and tonsil tissues taken on the same slide was used as external control. Cytoplasmic and membranous staining in tumor cells and TILs were evaluated and recorded separately. While membranous staining above $1 \%$ in tumor cells was accepted as positive, all other staining was accepted as negative.

Combined positive score (CPS) was also calculated per case according to the Collage of American Pathologists' June 2021 guidelines defined for gastrointestinal organs. ${ }^{22}$

CPS $=$ PD-L1 positive cells (tumor cells, lymphocytes, and macrophages $) \div$ Total of $\mathrm{PD}$-L1 positive $+\mathrm{PD}$-L1 negative tumor cells $\times 100$.

\section{Evaluation of Stromal Response (Desmoplasia)}

Hematoxylin-eosin sections prepared from each case were examined, and tumor stroma was evaluated in terms of cellularity and extracellular material accumulation. Depending on whether they were rich or poor in cells such as inflammatory cells,

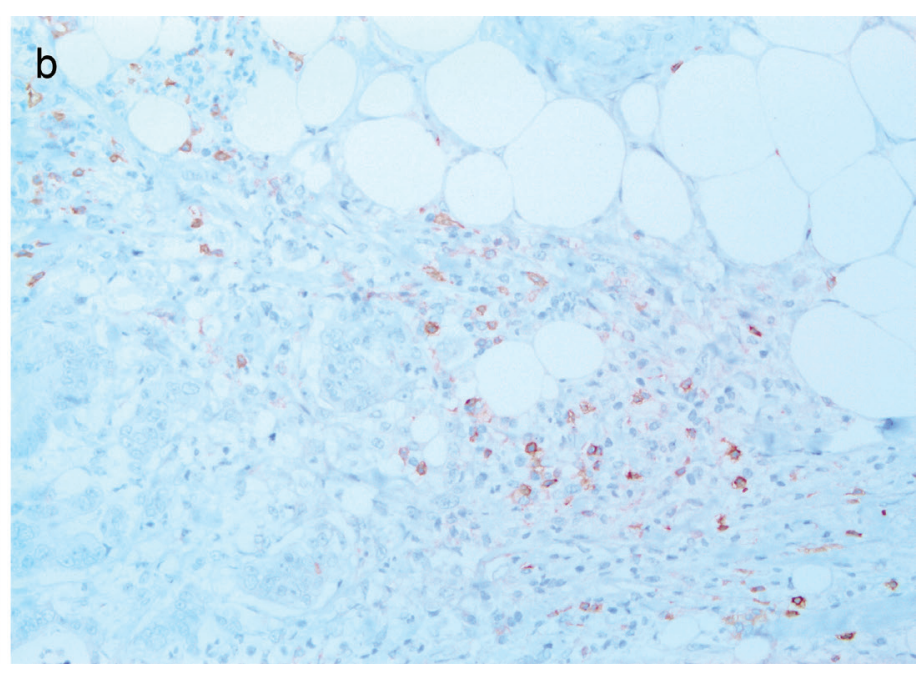

FIG. 1 a,b. Immunostaining for CD103 antibody, (a) CD103 staining of 1 hot spot in tumor area, (b) CD103 staining of 1 hot spot in peritumoral area. (Immunohistochemistry CD103 antibody, x200 and x400). 


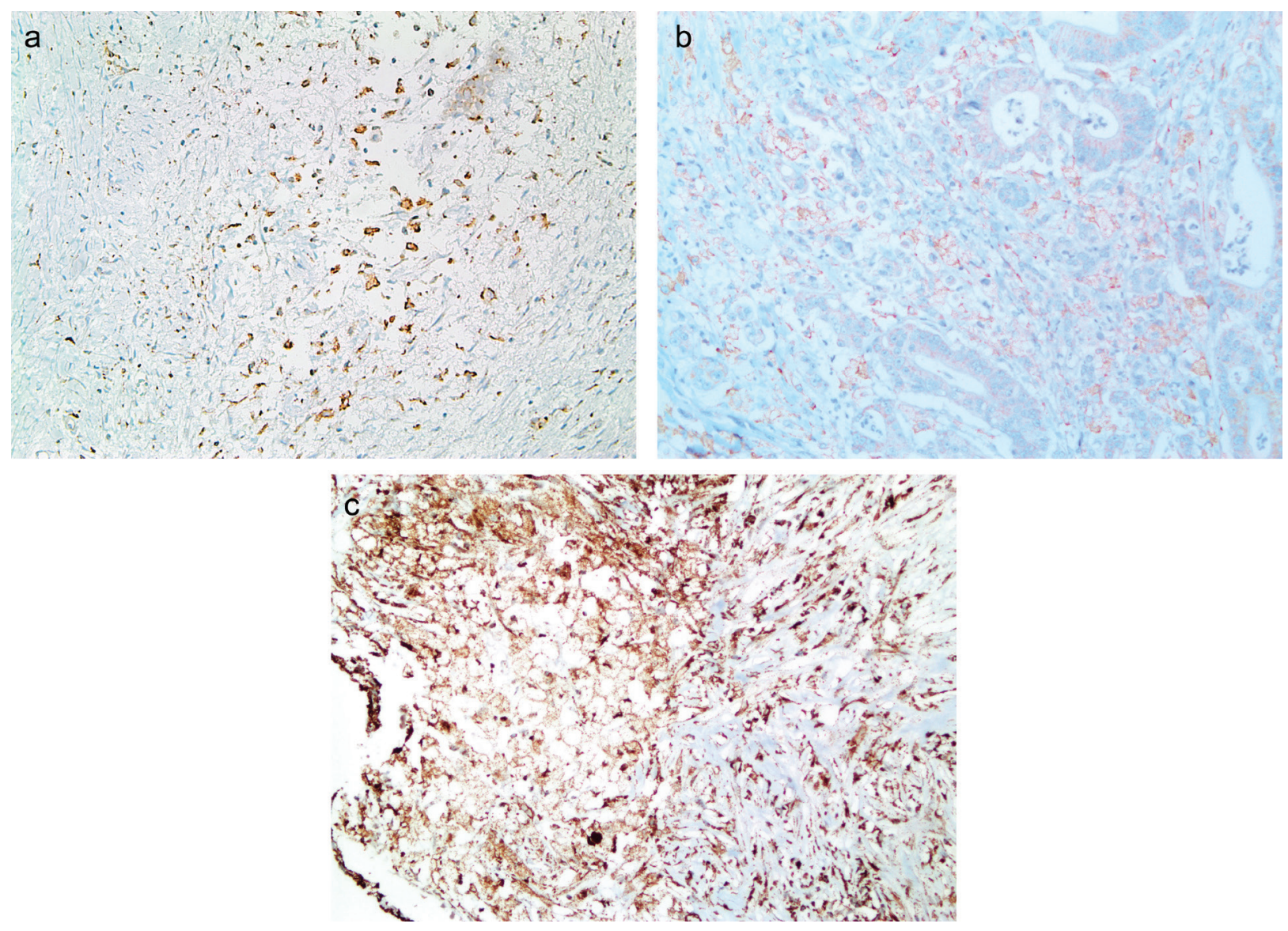

FIG. 2 a-c. Immunostaining of macropahaes for CD204 in tumor area, (a) minimal-score 1, (b) moderate-score 2, (c) maximum-score 3 (Immunohistochemistry CD103 antibody, x400).

myofibroblasts and fibroblasts stromal response was scored as 1-3. Score 1: stroma is rich in cells and less extracellular matrix; score 2: stroma has equal cell quantity and extracellular matrix ratio; score 3: stroma is poor of cells but has abundant extracellular matrix (Figure 3a-c).

Presence of peritumoral Crohn's-like inflammatory response (CLR) was also noted (Figure 4).

\section{Statistical Analysis}

Regularly distributed data were expressed using mean standard deviation, and non-uniformly distributed data were expressed using median values. Chi-square test was used for the comparison of categorical data. Comparison of the continuous data was made by determining the distribution pattern using Kolmogorov-Smirnov and Shapiro-Wilk tests.

Disease-free survival time (DFS) was defined from the date of the operation to the date of recurrence or to the date of the last visit (months) if the patient was still alive.

Overall survival time (OS) was defined as the time from the date of initial diagnosis to the date of death or the date of the last visit (months) if the patient was still alive.
During the statistical analysis, median values calculated as cut-off values for TRM counts were accepted which was consistent with the literature.

CD204+ TAMs groups were combined into two groups according to their intensity (score 1: minimal and intermediate intensity and score 2: maximum intensity).

Kaplan-Meier method was used for survival analysis and logrank test was used for univariate analysis. In order to determine prognostic factors for survival, a Cox regression model was created with variables that were statistically significant or nearly significant $(P<.1)$ in univariate analysis. Since statistically significant results could not be obtained in univariate analysis, multivariate analysis was not performed.

Based on findings that reported better prognosis with high intra-tumoral TRM cells in lung, breast, colorectal cancers, we hypothesized that having high (more than median value) intra-tumoral TRM cells will predict better DFS in curatively resected pancreatic adenocarcinoma at 18 months. Our patient population was largely treated with gemcitabine in adjuvant setting. Disease-free survival rate of standard treatment arm (gemcitabine alone) in PRODIGE 24-ACCORD trial was about 

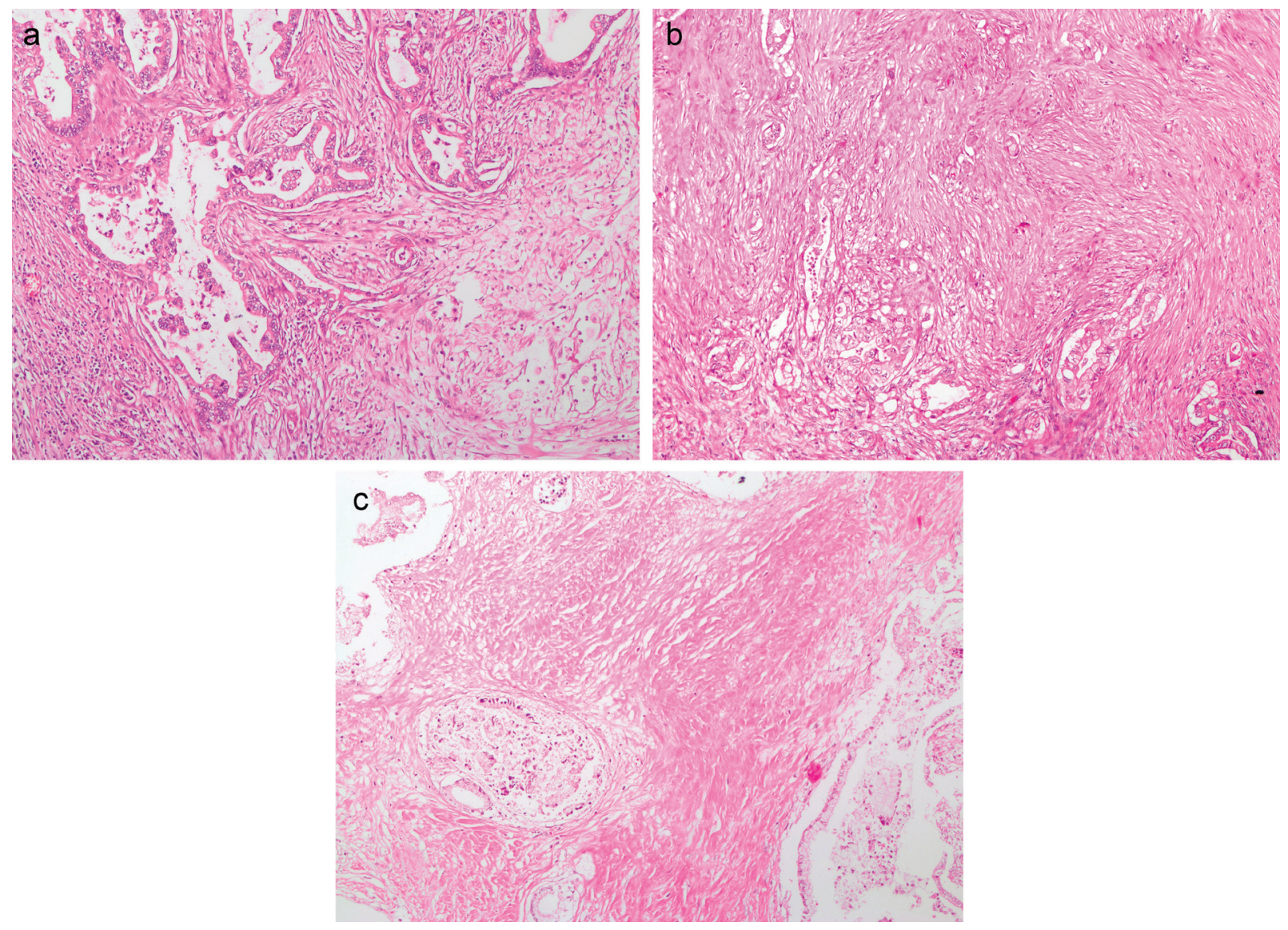

FIG. 3 a-c. Stromal response. (a) Score 1: stroma rich in cells and less extracellular matrix; (b) Score 2: stroma with equal cell quantity and extracellular matrix ratio; (c) Score 3: the stroma with poor of cells but with abundant extracellular matrix (H\&E staining, x200).

$40 \%{ }^{23}$ We hypothesized that an absolute $20 \%$ improvement will be observed in a patient with high intratumoral TRM cells. We calculated that this study must include complete data of 75 patients in each group to have $80 \%$ power with a $5 \%$ type I

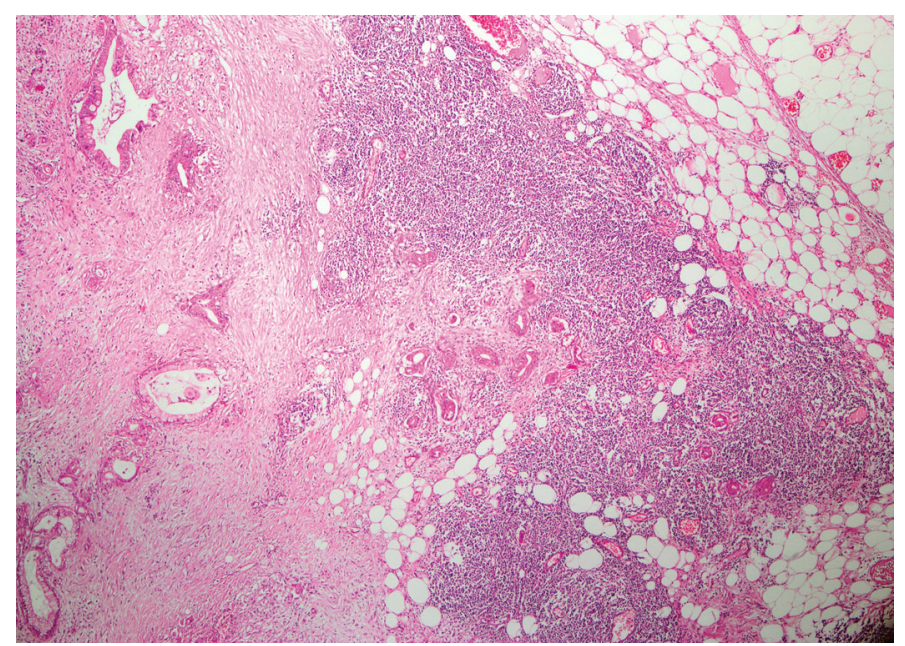

FIG. 4. Peritumoral Crohns'-like lymphoid response (H\&E staining, $\mathrm{x} 100)$. error level to detect a minimum clinically significant difference of $20 \%$ improvement in DFS, when the expected DFS at 18 months is $40 \%$ in the control group. Confidence interval for statistical significance was accepted as $95 \%$ and a two-sided $P$ value $<.05$. The data were evaluated with the software "SPSS 22.0".

\section{RESULTS}

A total of 81 patients diagnosed with PDAC were included in the study, with a male predominance (56.8\%). Median age at diagnosis was 63 (range: 40-78) years.

Histology of all tumors were adenocarcinoma. Most of the tumors $(80.2 \%)$ were located in the head of the pancreas. Descriptive characteristics are given in Table 1. Five patients did not receive adjuvant chemotherapy (CT) due to poor performance status, delayed wound healing, or patient-related reasons. Forty-two $(51.9 \%)$ patients received adjuvant radiotherapy (RT) in addition to adjuvant $\mathrm{CT}$.

\section{Survival Analysis}

The median follow-up period was 18.9 months (range 1.4-80.4 months). In the final analysis, $68(84 \%)$ patients had relapsed 
TABLE 1. Descriptive Characteristics

\begin{tabular}{|c|c|}
\hline Descriptives & Patients, n (\%) \\
\hline \multicolumn{2}{|l|}{ Gender } \\
\hline Male & $46(56.8)$ \\
\hline Female & $35(43.2)$ \\
\hline \multicolumn{2}{|c|}{ Diagnostic age } \\
\hline$<60$ years & $36(44.4)$ \\
\hline$\geq 60$ years & $45(55.6)$ \\
\hline \multicolumn{2}{|l|}{ ECOG PS } \\
\hline PS 0-1 & $75(92.6)$ \\
\hline PS 2-3 & $6(7.4)$ \\
\hline \multicolumn{2}{|c|}{ Location of tumor } \\
\hline Head & $65(80.2)$ \\
\hline Corpus & $5(6.2)$ \\
\hline Tail & $11(13.6)$ \\
\hline \multicolumn{2}{|l|}{ Grade groups } \\
\hline Grade $<3$ & $64(79)$ \\
\hline Grade $\geq 3$ & $17(21)$ \\
\hline \multicolumn{2}{|l|}{ T stage } \\
\hline $\mathrm{T} 1-2$ & $54(66.7)$ \\
\hline T3-4 & $27(33.3)$ \\
\hline \multicolumn{2}{|l|}{$\mathrm{N}$ stage } \\
\hline Positive & $19(23.5)$ \\
\hline Negative & $62(76.5)$ \\
\hline \multicolumn{2}{|l|}{ Stage groups } \\
\hline Stage I & $12(14.8)$ \\
\hline Stage II & $41(50.6)$ \\
\hline Stage III & $28(34.6)$ \\
\hline \multicolumn{2}{|l|}{ PNI } \\
\hline No & $6(7.4)$ \\
\hline Yes & $75(92.6)$ \\
\hline \multicolumn{2}{|l|}{ LVI } \\
\hline No & $11(13.6)$ \\
\hline Yes & $70(86.4)$ \\
\hline \multicolumn{2}{|c|}{ Surgical margin } \\
\hline Negative & $38(46.9)$ \\
\hline Positive & $43(53.1)$ \\
\hline
\end{tabular}

and $56(69.1 \%)$ patients had died. Median OS was 23.7 months (1.4-80.4 months) and median DFS was 10.8 months (1.4-74.4 months).

According to pathological evaluation, patients with above-median intra-tumoral TRM cells had longer survival trend than those having below-median values (25.6 months vs. 18 months, respectively, $P$ $=.84$ ) (Table 2).

As we presented in Table 3, lower stromal score (defined as having less desmoplasia and more cells in stroma) and/or presence of peritumoral CLR were associated with a higher survival trend in microenvironment evaluation (29.7 months vs. 19.7 months for lower vs. higher stroma score, $P=.16$ and 30.2 months vs. 18.1 months for positive vs. negative CLR, $P=.13$ ). However, decreased survival trend was seen in tumors with increased CD204+ TAMs which were immunosuppressive elements of the microenvironment (26.3 months vs. 12 months for lower CD204+ TAMs vs. higher respectively, $P=.29$ ). Membranous PDL1 positivity in tumor cells was detected in only 1 case. However, when we evaluated 'combined positive score' to detect PDL1 positivity, we determined 29 (35.8\%) PDL-1 positive cases. Patients with positive PDL-1 combined score did not reveal any significant correlation with the survival but also had a higher survival trend (30.6 months vs. 17 months, $P=.57$ ).

Kaplan-Meier survival curves according to pathological evaluations are presented in Figure 5a-e.

Multivariate analysis was not performed because there was no statistically significant variable in univariate analysis.

\section{DISCUSSION}

Understanding the immunogenicity of pancreatic carcinoma is the main idea of this study. Here we investigated the prognostic value of TRM and TME which has previously been shown to be valuable in different types of immunogenic solid tumors, with insufficient data for pancreatic carcinoma in the literature. Despite inflammatory cells being concentrated around the tumor, there is a low number of TILs in the tumor center in pancreatic carcinoma which is also known as a cold tumor. ${ }^{3}$

Tissue-resident memory $\mathrm{T}$ cells which are known to be closely linked to tumor immune response were detected to be higher in peritumoral stroma than the center of tumor in this study. On the other hand, it has been shown in the literature that an excess number of TRM in the tumor center is associated with increased survival. ${ }^{24,25}$ We determined a higher survival trend in the group of patients with higher intra-tumoral TRM cells (25.6 months intratumoral vs. 18 months peritumoral, respectively, $P=.84$ ).

Therefore, these findings support the point that peritumoral TRMs are not as effective as intra-tumoral TRMs. We believe that the factor affecting survival might not be the TILs count alone but it might also be the penetration of lymphocytes into tumor. Most probably tumor tissue might be blocking the penetration of effective immune cells like TRMs through barriers. 
In accordance with the hypothesis of the inactivation of lymphocytes outside the tumor, we evaluated CLR in our study. Crohn's-like inflammatory response indicates an active lymphoid reaction and an increased adaptive immune response to the tumor. It has been previously described as a host response to tumor in colon cancer, and increased CLR was associated with prolonged survival for colon cancer. ${ }^{26,27}$ This has not been previously reported for pancreatic cancer in the literature. Active lymphocytes might be the other important factors that reflect immune response and improve survival regardless of TILs count substantially in our study. Patients with higher CLR scores showed a higher survival trend (30.2 months vs. 18.1 months, $P=.13$ ).

Similarly, desmoplastic stroma which has abundant extracellular matrix and lower inflammatory cells reflects a poor immune response to cancer. ${ }^{28}$
In this study, the patients who have high stroma score showed better OS numerically (29.2 months vs. 19.2 months, $P=.16$ ).

CD204+ TAMs, which are another valuable element of TME, contribute to immunosuppressive microenvironment. Previous studies have shown that higher CD204+ TAMs in pancreatic cancer are associated with a poor prognosis. ${ }^{20,29}$ In our study, a shorter survival trend correlated with an increased total number of CD204+ TAMs (either intra-tumoral or peri-tumoral) which is consistent with the literature.

Finally, variable results between 1 and $60 \%$ have been reported for PDL1 expression in pancreatic cancers in the literature. ${ }^{30,31}$ Prognostic value of PDL1 either in tumor cells or tumor-associated inflammatory cells has not been proven yet. We detected only 1 tumor positive for PDL1 (1.2\%) and 37\% in tumor-associated inflammatory cells in our study, which was also reported by

TABLE 2. Univariate Analysis According to Tissue Resident Memory Cells

\begin{tabular}{|c|c|c|c|c|c|c|c|}
\hline Categorical Variables & $\mathrm{n}$ & OS (months) & $95 \% \mathrm{CI}$ & $P$ & DFS (months) & $95 \% \mathrm{CI}$ & $P$ \\
\hline \multicolumn{8}{|l|}{ TRM cells - intratumoral } \\
\hline \multicolumn{8}{|c|}{ Groups according to median } \\
\hline$\leq 8$ & 42 & 18 & $2-39$ & .84 & 8.0 & $3.6-12.4$ & .80 \\
\hline$>8$ & 39 & 25.6 & $19.0-32.2$ & & 12.6 & $8.7-16.6$ & \\
\hline \multicolumn{8}{|l|}{ TRM cells - peritumoral } \\
\hline \multicolumn{8}{|c|}{ Groups according to median } \\
\hline$\leq 43$ & 40 & 29.2 & $23.18-35.29$ & .198 & 13.4 & $7.2-19.5$ & .15 \\
\hline$>43$ & 41 & 17 & $10.19-23.84$ & & 7.8 & $4.6-11.0$ & \\
\hline
\end{tabular}

OS, overall survival; DFS disease-free survival; TRM, tissue-resident memory; CI, confidence interval.

TABLE 3. Univariate Analysis According to Microenvironment Features

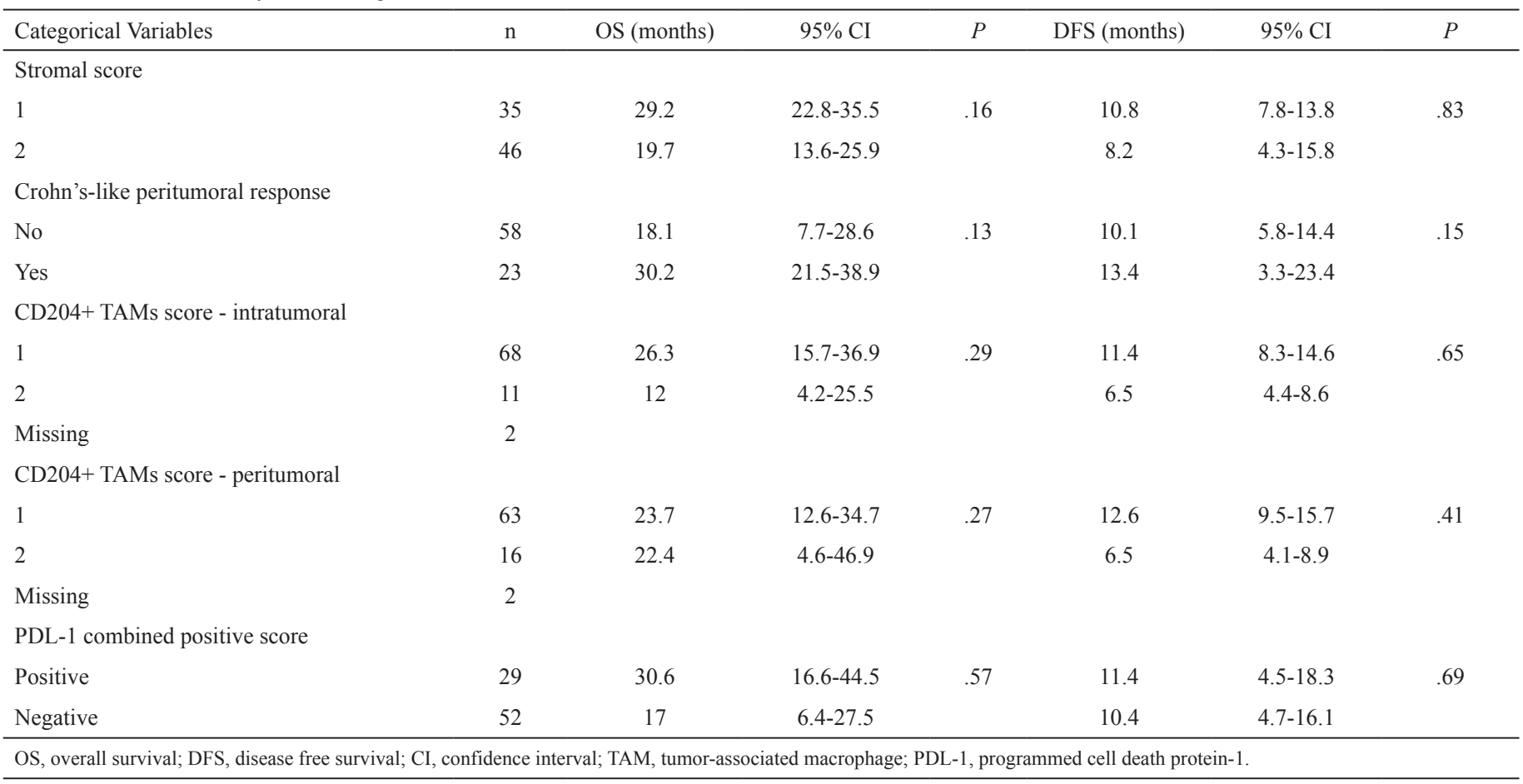



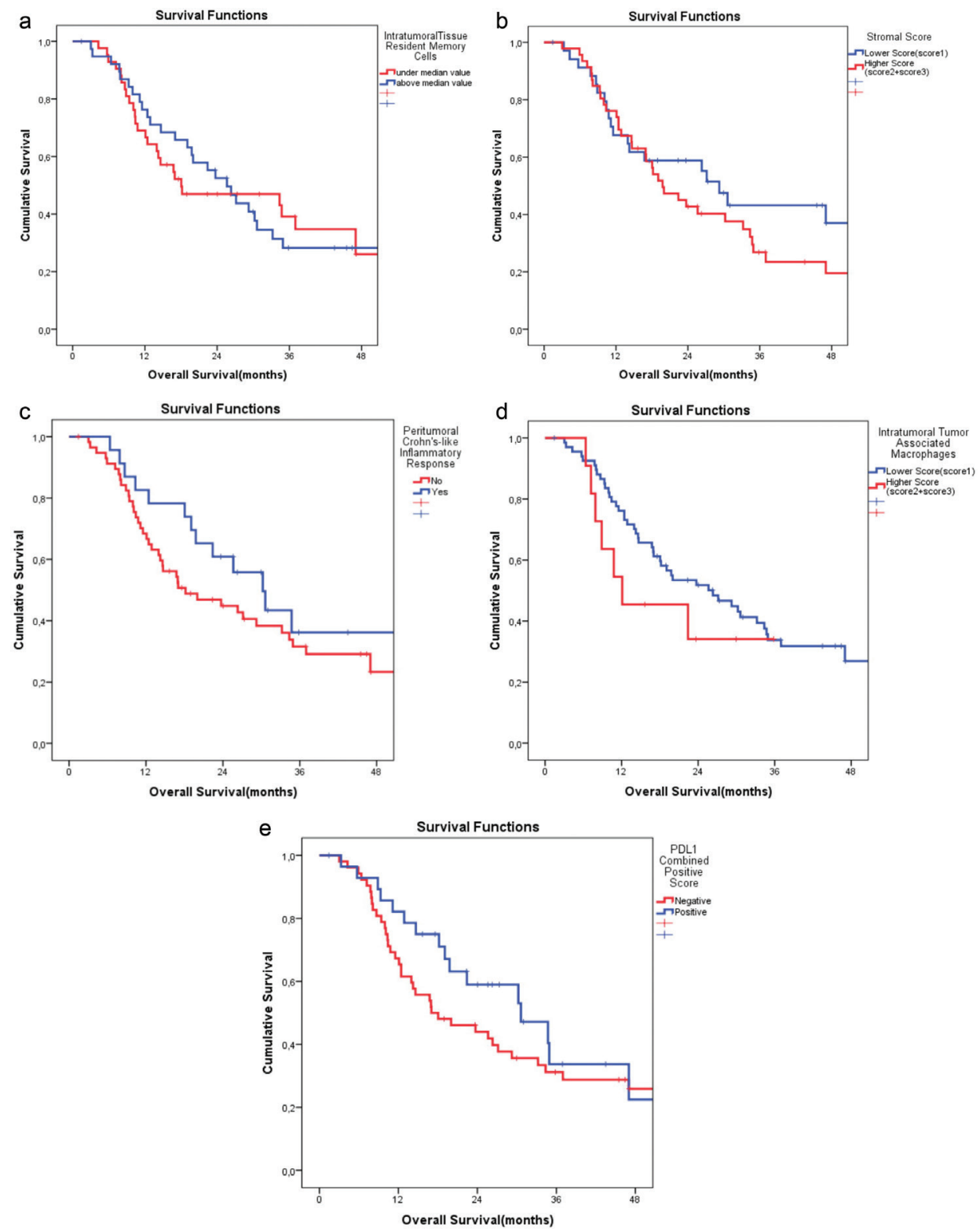

FIG. 5 a-e. Kaplan-Meier survival curves according to tumor characteristics. (a) Intratumoral tissue-resident memory T cells, (b) stromal score, (c) peritumoral Crohn's-like inflammatory response, (d) intratumoral tumor-associated macrophages, (e) PDL1 combined positive score.

Herbst et al. ${ }^{31}$ They reported higher PDL1 positivity in tumorassociated inflammatory cells than in tumor cells. The importance of 'PDL-1 combined score' for gastrointestinal tumors has been emphasized in the updated College of American Pathologists (CAP) Protocols in June 2021, but it was also controversial for gastrointestinal tumors in the literature. ${ }^{32-35}$ Twenty-nine patients for whom we detected a positive combine score for PDL-1 had higher survival numerically (30.6 months vs. 17 months, $P=.57$ ). Our statistically insignificant results might also be related to small sample.

In conclusion, despite our statistically insignificant results, the positive survival trend suggests that TRM, TAM, CLR, and stromal cellularity/matrix ratio may have prognostic significance in pancreatic cancer. The small number of sample is the restrictive factor for this study. Further studies are needed to improve our results and to investigate other mechanisms underlying PDAC immunogenicity.

Ethics Committee Approval: Ethics/Institutional Review Board approval of ResearchSchool of Medicine Marmara University, İstanbul, Turkey (ethical approval no: 09.2019.483).

Patient Consent for Publication: Written informed consent was obtained from all patients.

Data Sharing Statement: The data that support the findings of this study are available from the corresponding author upon reasonable request. 
Author Contributions: Concept - T.B., N.B., P.B.; Design - T.B., N.B., P.B.; Supervision - N.B., P.B., F.Y.; Data Collection and/or Processing - T.B., E.A., F.E.Ö., N.C.D., R.A., T.A.T., O.E.; Analysis and/or Interpretation - M.A.Ö.; Literature Review - T.B.; Writing - T.B.; Critical Review - F.Y.

Conflict of Interest: The authors have no conflicts of interest to declare.

Funding: This work has been supported by Marmara University Scientific Research Projects Coordination Unit under grant number SAG-C-TUP-120619-0217 and Turkish Society of Medical Oncology.

\section{REFERENCES}

1. Stewart BW, Kleihues P. World Cancer Report 2003. Lyon, France: International Agency for Research on Cancer (IARC); 2003. [CrossRef]

2. Provenzano PP, Cuevas C, Chang AE, Goel VK, Von Hoff DD, Hingorani SR. Enzymatic targeting of the stroma ablates physical barriers to treatment of pancreatic ductal adenocarcinoma. Cancer Cell. 2012;21(3):418-429. [CrossRef]

3. Bonaventura P, Shekarian T, Alcazer V, et al. Cold tumors: a therapeutic challenge for immunotherapy. Front Immunol. 2019;10:168. [CrossRef]

4. Lohneis $\mathrm{P}$, Sinn M, Bischoff S, et al. Cytotoxic tumour-infiltrating T lymphocytes influence outcome in resected pancreatic ductal adenocarcinoma. Eur J Cancer. 2017;83:290-301. [CrossRef]

5. Peranzoni E, Lemoine J, Vimeux L, et al. Macrophages impede CD8 T cells from reaching tumor cells and limit the efficacy of anti-PD-1 treatment. Proc Natl Acad Sci USA. 2018;115(17):E4041-E4050. [CrossRef]

6. Jiang X. Skin-delivered vaccines. Sci-Bus Exch. 2012;5(12):319. [CrossRef]

7. Zhou YW, Komada Y, Inaba H, et al. Functional significance of adhesion molecules in Fas-dependent apoptotic cell death induced by interleukin-2-activated $\mathrm{T}$ cells. Immunol Invest. 1998;27(4-5):309-322. [CrossRef]

8. Karayiannakis AJ, Syrigos KN, Chatzigianni E, et al. Aberrant E-cadherin expression is associated with loss of differentiation and advanced stage in human pancreatic cancer. Anticancer Res. 1998;18(6A):4177-4180. [CrossRef]

9. Kilshaw PJ, Murant SJ. A new surface antigen on intraepithelial lymphocytes in the intestine. Eur J Immunol. 1990;20(10):2201-2207. [CrossRef]

10. May TMT. Breaking advances. Cancer Res. 2011;71:291-626.

11. Djenidi F, Adam J, Goubar A, et al. CD8+ CD103+ tumor-infiltrating lymphocytes are tumor-specific tissue-resident memory $\mathrm{T}$ cells and a prognostic factor for survival in lung cancer patients. J Immunol. 2015;194:3475-3486. [CrossRef]

12. Byrne A, Savas P, Sant S, et al. Tissue-resident memory T cells in breast cancer control and immunotherapy responses. Nat Rev Clin Oncol. 2020;17(6):341-348. [CrossRef]

13. Park SL, Buzzai A, Rautela J, et al. Tissue-resident memory CD8+ T cells promote melanoma-immune equilibrium in skin. Nature. 2019;565(7739):366-371. [CrossRef]

14. Webb JR, Milne K, Watson P, DeLeeuw RJ, Nelson BH. Tumor-infiltrating lymphocytes expressing the tissue resident memory marker CD103 are associated with increased survival in high-grade serous ovarian cancer. Clin Cancer Res. 2014;20(2):434-444. [CrossRef]

15. Quinn E, Hawkins N, Yip YL, Suter C, Ward R. CD103+ intraepithelial lymphocytes - a unique population in microsatellite unstable sporadic colorectal cancer. Eur J Cancer. 2003;39(4):469-475. [CrossRef]

16. Mami-Chouaib F, Blanc C, Corgnac S, et al. Resident memory $\mathrm{T}$ cells, critical components in tumor immunology. J Immunother Cancer. 2018;6(1):87. [CrossRef]

17. Nizard M, Roussel H, Diniz MO, et al. Induction of resident memory $\mathrm{T}$ cells enhances the efficacy of cancer vaccine. Nat Commun. 2017;8(1):15221. [CrossRef]

18. Edwards J, Wilmott JS, Madore J, et al. CD103+ tumor-resident CD8+ T cells are associated with improved survival in immunotherapy-naive melanoma patients and expand significantly during anti-PD-1 treatment. Clin Cancer Res. 2018;24(13):30363045. [CrossRef]

19. Pollard JW. Tumour-educated macrophages promote tumour progression and metastasis. Nat Rev Cancer. 2004;4(1):71-78. [CrossRef]

20. Kurahara H, Shinchi H, Mataki Y, et al. Significance of M2-polarized tumor-associated macrophage in pancreatic cancer. J Surg Res. 2011;167(2):e211-e219. [CrossRef]

21. Hirayama S, Ishii G, Nagai K, et al. Prognostic impact of CD204-positive macrophages in lung squamous cell carcinoma: possible contribution of CD204positive macrophages to the tumor-promoting microenvironment. J Thorac Oncol. 2012;7(12):1790-1797. [CrossRef]

22. Alexander BJD, Brett WB, Andrew MB, George GBPL, Frank S, Raja RS. Template for reporting results of quantitative IHC biomarker testing of specimens from patients with carcinoma. version 1.0.0.0. Illinois, USA: College of American Pathologists; 2021. https://documents.cap.org/protocols/IHC.Bmk_1.0.0.0.REL_CAPCP.pdf [CrossRef]

23. Conroy T, Hammel P, Hebbar M, et al. FOLFIRINOX or gemcitabine as adjuvant therapy for pancreatic cancer. N Engl J Med. 2018;379(25):2395-2406. [CrossRef]

24. Miksch RC, Schoenberg MB, Weniger M, et al. Prognostic impact of tumorinfiltrating lymphocytes and neutrophils on survival of patients with upfront resection of pancreatic cancer. Cancers. 2019;11(1). [CrossRef]

25. Ino Y, Oguro S, Yamazaki-Itoh R, Hori S, Shimada K, Hiraoka N. Reliable evaluation of tumor-infiltrating lymphocytes in pancreatic cancer tissue biopsies. Oncotarget. 2019;10(10):1149-1159. [CrossRef]

26. Graham DM, Appelman HD. Crohn's-like lymphoid reaction and colorectal carcinoma: a potential histologic prognosticator. Mod Pathol. 1990;3(3):332-335. [CrossRef]

27. Maoz A, Dennis M, Greenson JK. The Crohn's-like lymphoid reaction to colorectal cancer-tertiary lymphoid structures with immunologic and potentially therapeutic relevance in colorectal cancer. Front Immunol. 2019;10:1884. [CrossRef]

28. Cannon A, Thompson C, Hall BR, Jain M, Kumar S, Batra SK. Desmoplasia in pancreatic ductal adenocarcinoma: insight into pathological function and therapeutic potential. Genes Cancer. 2018;9(3-4):78-86. [CrossRef]

29. Liyanage UK, Moore TT, Joo HG, et al. Prevalence of regulatory T cells is increased in peripheral blood and tumor microenvironment of patients with pancreas or breast adenocarcinoma. J Immunol. 2002;169(5):2756-2761. [CrossRef]

30. Lu C, Paschall AV, Shi H, et al. The MLL1-H3K4me3 axis-mediated PD-L1 expression and pancreatic cancer immune evasion. J Natl Cancer Inst. 2017;109(6). [CrossRef]

31. Herbst RS, Soria JC, Kowanetz M, et al. Predictive correlates of response to the antiPD-L1 antibody MPDL3280A in cancer patients. Nature. 2014;515(7528):563-567. [CrossRef]

32. Zhao L, Cao Y. PD-L1 expression level displays a positive correlation with immune response in pancreatic cancer. Dis Markers. 2020;2020:8843146. [CrossRef]

33. Yamashita K, Iwatsuki M, Harada K, et al. Prognostic impacts of the combined positive score and the tumor proportion score for programmed death ligand-1 expression by double immunohistochemical staining in patients with advanced gastric cancer. Gastric Cancer. 2020;23(1):95-104. [CrossRef]

34. Kulangara K, Zhang N, Corigliano E, et al. Clinical utility of the combined positive score for programmed death ligand-1 expression and the approval of pembrolizumab for treatment of gastric cancer. Arch Pathol Lab Med. 2019;143(3):330-337. [CrossRef]

35. Hu Y, Chen W, Yan Z, Ma J, Zhu F, Huo J. Prognostic value of PD-L1 expression in patients with pancreatic cancer: a PRISMA-compliant meta-analysis. Med. 2019;98(3):e14006. [CrossRef] 